\title{
DINAMISMO SISTÉMICO EN LA DIACRONÍA DE LA LENGUA ESPAÑOLA
}

Vidal Lamíquiz

$U N E D$

1. Metodologia SISTÉmica

\subsection{Modelos de diacronía}

No es difícil coincidir con Th. Bynon (1981), quien distingue tres grandes modelos de interpretación del cambio lingüístico: el neogramático, el estructural y el generativo. Y pensamos que continúa teniendo razón cuando afirma que "el modelo neogramático es la base esencial sobre la que se levantaron los modelos estructuralista y el generativo que no constituyen otra cosa que elaboraciones y modificaciones de aquél" (Ibidem: 34 ).

Por ello, sea cual sea el modelo histórico que hoy adoptemos en la investigación diacrónica de la lengua, podemos afirmar con Robins: "todos somos neogramáticos" (R.H. Robins, 1984: 182). Bien es verdad que, por un proceso de actualización metodológica, siempre quedará matizada esa afirmación por una tendencia que revele la inclinación hacia alguno de los modelos posteriores.

\subsubsection{El modelo neogramático}

Efectivamente, los neogramáticos son los primeros en ofrecer una formulación ordenada y coherente del conjunto de conocimientos de 
la historia de las lenguas y de sus relaciones mutuas en comparación, desde finales del siglo xvirl. A ellos debemos dos importantes principios:

1) La sistematicidad del cambio

2) El reconocimiento de dos grandes fuerzas en ese cambio: el cambio fonético y la analogía.

Si mucho lograron en la comparación de lenguas y en la reconstrucción de protolenguas, en el campo del estudio histórico de lenguas particulares aportaron, a nuestro juicio, un mayor rigor en ese estudio histórico así como una formulación del problema del orden y forma de las leyes fonéticas que, hasta ese momento, no habían recibido un tratamiento sistemático.

Bien es cierto que la manera como los neogramáticos trataron las formas irregulares de la lengua, propició el éxito subsiguiente del llamado modelo estructural.

\subsubsection{El modelo estructuralista}

Efectivamente, la interpretación estructural del cambio lingüístico en el nivel de expresión gira en torno a dos ejes: 1) el resultado de un cambio fonético en el sistema fonológico de la lengua y 2) el estudio del cambio fonético "desde el punto de vista de la causación sistemática" (R.H. Robins, Idem: 220 y ss).

En cuanto al primero de esos dos ejes, la labor de la Escuela de Praga consistió en "reclasificar" o "reescribir" algunos de los cambios fonéticos atendiendo a sus consecuencias en el sistema fonológico. Se crean los conceptos de fonologización, desfonologización y transfonologización. Con la atención puesta en el armazón de rasgos distintivos, se hace posible establecer, de manera precisa y económica, el efecto de un cambio sobre la estructura interna del conjunto sistémico, con lo cual nos situamos en el segundo eje.

Y atendiendo a la "cadena de tracción" o "cadena de propulsión" que se instala en el interior del sistema, se desarrolla la teoría de las casillas vacías.

Ello nos conduce a dos criterios frecuentemente empleados por A. Martinet:

1) El rendimiento funcional de una determinada oposición que opere en el sistema ya que cuanto mayor sea su rendimiento, 
menor será la posibilidad de que se produzca su cambio y viceversa.

Este criterio es empíricamente discutible. El mismo B. Malmberg, defensor de la teoría estructural, duda de la importancia de este factor de rendimiento funcional y señala oportunamente que no opera solo y se conserva tanto más fácilmente cuanto mayor es su implicación en una correlación (B. Malmberg, 1966: 149).

2) El criterio de economía que supone una renovación en el estudio. del campo lingüístico, criterio económico entendido como el resultado de la interacción de dos fuerzas en conflicto: por un lado, las exigencias de la comunicación y, por otra parte, la inercia humana con su tendencia a reducir al mínimo su actividad mental o física (A. Martinet, 1964: 281), ley del menor esfuerzo que se reinterpreta más ampliamente como economía.

Esta es, a nuestro entender, la mayor aportación de los criterios estructurales a la teoría del cambio histórico, en la medida en que es integradora e intenta conciliar las explicaciones estrictamente fisiológicas o de substrato del modelo neogramático anterior con el estudio estructural de la lengua.

Además, es innegable que el modelo estructural proporciona un buen instrumento para captar la distinción entre lo fonológico y lo fonético así como para comprender la adaptación de los préstamos, dice C. Pensado (1983: 166).

Ahora bien, una cronología que se basa en argumentos puramente internos, añade $\mathrm{C}$. Pensado, puede fallar por haberlos malinterpretado y forzosamente dejará zonas enteras de la historia de la lengua sin aclarar; pero una reconstrucción que se fundamenta en una teoría previa que explica las evoluciones, no sólo puede fallar por las causas antes señaladas, sino que, además, está condicionada por la aceptación previa de las teorías que supone, de modo que, por principio, sus conclusiones no son probatorias para quien no acepte aquéllas (C. Pensado, 1983: 42).

En consecuencia, la explicación de las secuencias de cambio tiene que ser posterior a la reconstrucción de la secuencia que explica. Y cada reconstrucción requiere el conjunto de innovaciones que provienen de tres órdenes de causas:

a) De la evolución interna del sistema, una relación simple entre los componentes de la estructura y las casillas vacías que ofrezca en un momento estable dado. 
b) De la evolución relativa al tener en cuenta la situación "cotextual", o sea las reglas de interacción de las unidades vecinas en el sintagmatismo lineal de la palabra (veáse C. Pensado, 1984: passim).

c) De la evolución condicionada por influencia del entorno ambiental, la situación "contextual", histórico-cultural.

Es decir, de la interrelación interactiva de las diversas fuerzas simultáneas que actúan desde esas tres causas complejas de cambio, brotará la reconstrucción.

Por lo dicho, la aplicación de un criterio estructural ortodoxo no nos parece conveniente ya que considera únicamente en el sistema, por el sistema y desde el sistema todo cambio. Así coincidimos con E. Coseriu (1977: 219 nota 63) al entender que "el enfoque estructural debe completarse con otros, igualmente válidos y necesarios".

\subsubsection{El modelo generativo}

El modelo generativo-transformativo no ha añadido gran cosa a la diacronía lingüística.

Sí es importante, sin embargo, el punto de vista externo que supone la Sociolingüística: la consideración del aspecto social de la lengua ya que éste implica un cambio latente. En este sentido, el estudio sociolingüístico exige y complementa al estudio histórico con un método muy cercano al de la lingǘstica comparada, o como un nuevo eslabón en el desarrollo de la dialectología tradicional (cfr Y. Malkiel, en J.P. Rona - W. Wölk (ed), 1976). Porque la causa de un cambio interno en el sistema suele ser una causa externa, según se ha dicho, o por lo menos, según hemos señalado en el tercer orden de causas anterior, participa en el cambio. De aquí la oportunidad y necesidad de contemplar la complejidad conjunta de diversas tendencias al cambio en la llamada regla variable de la sociolingüística (cfr W. Labov, 1972).

\subsection{Conclusión metodológica}

De lo expuesto, bien se puede deducir el criterio metodológico que aplicaremos en el estudio de la Historia de la Lengua Española. Un criterio sincrético no por comodidad sino por necesidad de exhaus- 
tividad ya que la explicación compleja de todo fenómeno histórico siempre se hallará en los tres argumentos de cambio analizados.

\section{DinAmisMo DiACRÓNICO}

\subsection{La tensión interna: predisposición al cambio}

Queremos completar nuestro criterio metodológico con la exposición, breve pero explícita, del concepto dinámico que atribuimos a todo sistema y, por tanto, del dinamismo del sistema de nuestra lengua española que a continuación vamos a aplicar a casos específicos de su diacronía.

Coincide con la concepción que muestra E. Coseriu (p.e. en "Determinación y entorno" en Teoría... 1962: 285; o en Estudios de lingǘstica románica, 1977: 262) al considerar la idea humboldtiana de que la lengua es energeia; y, por ello, al afirmar que la lengua "se da concretamente como actividad". En definitiva, se trata de una visión funcional donde el sistema lingüístico se ve come un sistema de posibilidades.

La clara repercusión para la historia de la lengua se percibe al considerar que, en el dinamismo operativo de las oposiciones instauradas en cada sistema estable, se da una insatisfacción sistemática que origina un cambio continuo o, por lo menos, una latencia preparada a la evolución. Sin esa tensión interna la estructura del sistema permanecería tal cual pero sin ser absoluta, algo teóricamente insoportable por la contradicción que entraña. La no tensión supondría un modo en permanencia del sistema, una sincronía que se mantendría estática en el eje de las sucesividades a pesar del dinamismo interno que opera en el eje de las simultaneidades.

La tensión interna del sistema, existente como oposiciones no conciliadas en su estructura, supone, pues, una tendencia a un cambio continuo, a una evolución constante, un caminar imparable hacia un teórico perfeccionamiento -la economía martinetiana-, perfección, a su vez, nunca alcanzada de manera absoluta.

Consecuencia insoslayable de esta situación tensa es la resistematización permanente de las estructuras, la regeneración constante que el conjunto sistémico experimenta, según contemplaremos en los casos que vamos a analizar. 


\subsection{La autorregulación: casillas vacías}

Un sistema, y no es excepción el sistema lingüístico, puede alcanzar una situación de estado estable cuando logra una optimización de adecuación de posibilidades para sus fines y objetivos.

La estabilidad no supone estaticismo ni inmovilidad, como podría deducirse lógicamente en la aplicación de un estructuralismo ortodoxo (véase L. Michelena, 1963: 217), ortodoxia que ya hemos rechazado anteriormente en nuestro enfoque metodológico. Porque, como señala E. Coseriu (1977: 134), en lo que concierne a la lengua histórica un sistema lingǘstico suele abarcar varios sistemas en litigio o varias normas que conviven en simultaneidad, o sea se ofrece como diasistema. Ello es, a la vez, causa y consecuencia de su dinamismo interno y obliga a contemplarlo en un equilibrio precario o, más bien, en un equilibrio relativo.

Porque el sistema lingüístico es abierto: permanentemente está dispuesto a importar y exportar materiales de su entorno y a acomodarlos en su organización interna. En esta actividad operan los circuitos reguladores que, en un servocontrol de autorregulación, propician el oportuno diseño en relación con los objetivos permanentes del conjunto sistémico. Así se mantiene en constancia homeostática o funcional.

Mas, para llegar a esta estabilidad, se tienen en cuenta las características teleológicas. La teleología de un sistema persigue un fin no alcanzado. Supone investigar para qué, por qué y cómo se lleva a cabo su mantenimiento en el todo sistémico. Y lo busca en un dinamismo en desequilibrio, siempre tendente al cambio y a la reestructuración, nunca satisfecho con el nuevo resultado, resultado que nunca es definitivo.

En su resistematización, el todo organizado sigue los modelos de adaptabilidad que le son idóneos y aprovechará las casillas vacías que nunca faltan en un sistema activo y vivo. Admitirá la alimentación o entrada del entorno ambiental y, en su interior, acomodará los nuevos elementos en su autorregulación. En nuevo estado sustituirá al anterior o, tras un tiempo de convivencia diasistémica, se impondrá por encima de él.

\section{Comportamiento historico sistémico en LA Lengua ESPAÑola}

Una vez precisada nuestra metodología y tras haber recordado los criterios lingüísticos en que fundamentamos nuestra investigación so- 
bre la historia de la lengua española, vamos a considerar unos casos ejemplificadores, algunos entre muchos posibles, donde se contempla la actividad del sistema en su dinamismo histórico.

En nuestra dedicación investigadora siempre hemos adoptado una perspectiva lingüística que, en visión exhaustiva, ni desdeña ni privilegia ninguna de las áreas metodológicas aceptadas unánimemente en la observación de la lengua. Por ello, recorreremos todas las infraestructuras de la lengua y contemplaremos el comportamiento histórico sistémico que atañe a la reestructuración dinámica en lo lexemático, en lo fonémico y en lo morfosintáctico; y no olvidamos lo sociolingüístico.

La obligada sucesividad expositiva no supone que no exista una gran interrelación entre esos diferentes niveles de la estructura: los casos que proponemos, no deben interpretarse como si funcionaran de manera aislada. Es más; pensamos que, a pesar de la atención preferente que en cada caso se dedica a uno u otro aspecto de la lengua, en todo momento se opera la interacción de todas las fuerzas: desde el entorno condicionante, desde lo gramatical, desde lo lexemático o desde lo fonémico. La tendencia evolutiva siempre proviene de varias causas interactuantes, más o menos potentes en cada circunstancia. En ese conjunto, la jerarquía desaparece. En definitiva, es en el sistema total donde los resultados se manifiestan.

\subsection{Comportamiento histórico sistémico en lo lexemático}

Opina L. Michelena (1967) que no es exagerado decir, probablemente, que son bastantes los estructuralistas que creen que el significado es tan importante por lo menos como los medios formales de que podemos valernos para expresarlo; son bastantes, en otras palabras, los que piensan que debe ser introducido francamente en el centro de nuestras preocupaciones y no dejado al margen para apelar a él cuando no quede otro recurso. Suponemos -añade- que en cualquier estado de lengua, histórico o prehistórico, los exponentes gramaticales y los elementos del léxico tienen contenidos más o menos precisos, definidos por oposiciones, que permiten su análisis en rasgos o componentes del significado, distintos de las simples variantes de su realización en el habla (1985: 19-20).

Coincidiendo con este criterio hemos prestado atención a este dominio lexemático en nuestro tabajo investigador.

Contemplemos, pues, un caso de comportamiento histórico sistémico en las estructuras lexemáticas de la lengua española que ya hemos señalado en otra ocasión (cfr V. Lamiquiz, 1985: 32). Y observemos el dinamismo sistémico que ofrece la actividad interna en las estructuras 
así como su virtualidad al propiciar el paso de un sistema estable a otro.

El término tenaza o tenazas hace referencia a "un instrumento de metal, compuesto de dos brazos trabados por un eje que permite abrirlos o cerrarlos, para coger o sujetar una cosa" (cfr DRAE, 1984: s.v. tenazas). Su presencia en la lengua se documenta ya en Berceo (J. Corominas - J.A. Pascual, 1983: s.v. tener).

Al lado de este término tenazas, nos encontramos con la presencia simultánea de otra unidad: tijera o tijeras, también documentada ya en Berceo (Idem, 1983: s.v. tundir I). Sus sucesivas grafías tiseras $\rightarrow$ tixeras $\rightarrow$ tigeras $\rightarrow$ tijeras corresponden al aspecto histórico fonémico de nuestra lengua. El valor significativo de esta unidad tijeras es "instrumento de metal, compuesto de dos hojas trabadas por un eje que permite abrirlas o cerrarlas, para cortar lo que se pone entre ellas" (DRAE, 1984: s.v. tijeras) y, como se observa, es paralelo.

Así, se ha instalado en el sistema una contraposición dialéctica

\author{
tenaza / tijera
}

dos unidades históricamente coexistentes que se mantienen en el sistema en coherencia, en razón de un choque opositivo de claro funcionamiento: cada una con tres rasgos sémicos, dos comunes que unen

'instrumento de metal'.

'dos brazos trabados por un eje que permite abrirlos o cerrarlos'

y otro tercer rasgo o marca sémica que diferencia y opone:

'para coger' / 'para cortar'

Incluso formalmente ofrecen similar comportamiento pues, si al lado de tenaza aparece tenazas, igualmente aparece tijera junto a tijeras en alomorfía léxica por un plural arrastrado por el rasgo sémico de los dos brazos $\mathrm{u}$ hojas.

En esta sencilla subestructura lexemática del castellano medieval 
se inserta el término pinzas, tomado del francés pinces = 'tenazas' y derivado de pincer = 'coger con tenazas' o 'pellizcar' (J. Corominas J.A. Pascual, 1983: s.v. pinzas). Se constituye como elemento lexemático de nuestra lengua, préstamo léxico pero reacomodado sémicamente como 'tenazas pequeñas' que se documenta hacia 1475.

No debe olvidarse que el léxico es la parte de la lengua que presenta los nexos más directos con la cultura material y espiritual de los hablantes y que las evoluciones semánticas sólo pueden ser comprensibles en referencia al fondo cultural, nos recuerda Th. Bynon (1981:96). En efecto, es conocida la fuerte influencia francesa en esa época medieval de nuestra lengua (cfr, principalmente, R. Lapesa, 1980: 219), especialmente en el léxico de los burgueses dedicados a la artesanía (Idem, 1984: 47), campo lexemático donde esos términos que contemplamos, se localizan.

En cuanto al sistema lexemático que organizan las unidades señaladas, comprobamos que se nos ofrece ya una estructura compleja

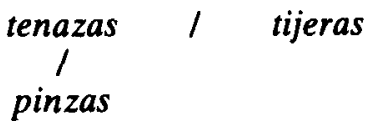

conjunto que, en posibles potencialidades, podemos verlo con la virtualidad de casillas vacías, las cuales, en el interno dinamismo reestructurante, aunque no solamente por él, podrían llenarse con nuevas unidades lexemáticas y originar posteriores estados sistemáticos estables. Así,

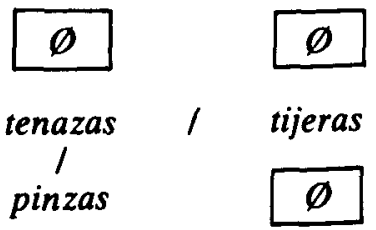

Porque, si se ha llenado con la unidad pinzas la casilla vacía correspondiene a 'tenazas pequeñas', ¿por qué no se llenará también la casilla que corresponde a la potencialidad de 'tenazas grandes'? ¿Y por qué no, continuando la correlación, los vacíos léxicos de 'tijeras pequeñas' o de 'tijeras grandes'? 
$Y$, en efecto, así ha seguido ocurriendo. En ese mismo ámbito semántico y sociocultural, desde los términos franceses ciseaux = 'tijeras' y cisailles = 'tijeras grandes para cortar planchas de metal', ya existentes en esta lengua francesa en el siglo XIII, y desde cisailler = 'couper avec les cisailles', según E. Littré (ed. 1958), se usa ya en 1450 el término cizaille con el valor de 'fragmento o cortadura de metal'.

Este término cizalla es tomado en préstamo por el castellano, como se atestigua por el Diccionario de Autoridades que le atribuye, más tarde en 1724, el valor de 'recortes de metal'. Y, por el proceso de expansión metonímica de contigüidad sémica, en el paso de la causa por la consecuencia, hacia 1600 (J. Corominas - J.A. Pascual, 1983: s.v. cincel) se documenta en nuestro sistema lexemático ese término de cizalla con el valor de 'tijeras grandes para cortar metales'.

Esta unidad lexemática, arrastrada igualmente al plural como las demás del conjunto, se instala en las estructuras que analizamos:

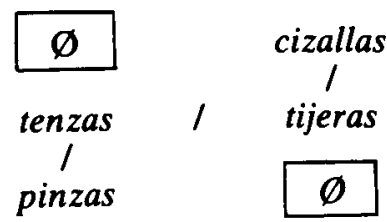

que se mantiene todavia en el sistema estable actual.

En definitiva, con una actitud de totalidad nos hemos percatado de la vitalidad del sistema y de sus potencialidades virtuales; cómo toma materiales del entorno sociocultural, en este caso préstamos léxicos del francés; cómo los acomoda y los hace suyos, modificando, cuando conviene, el valor originario; cómo opera el dinamismo interno estructurante; cómo cada estado estable que se origina permanece en dinámica tensión interna; cómo incluso el sistema actual operante continúa en esa misma tensión; cómo pueden aparecer otras estructuras futuras ya que permanece latente la capacidad virtual de saltar a otros posibles estados.

Las hipótesis posibles son calculables en la teleología funcional del sistema, según su rentabilidad comunicativa y en función de los modelos o diseños de adaptabilidad que son propios al español como lengua histórica. Las fuerzas interactivas, ya dentro del sistema mismo o bien en relación con el entorno ambiental condicionante sociocultural y sociolingüístico, desempeñan un importante papel lleno de complejidad, una complejidad que, sin caer en analogías antropomórficas, puede pensarse muy similar a la del desarrollo biológico de todo ser vivo. 


\subsection{Comportamiento histórico sistémico en lo fonémico}

En la fonología histórica el cambio de sistema es lo fundamental, decía R. Jakobson ya en 1931. Pero, en la síntesis de los criterios neogramático y estructuralista, se parte de una concepción fonética para alcanzar un sistema de oposiciones fonológicas definibles en un estado estable.

Vamos a contemplarlo en la historia de nuestra lengua española. Aquí, E. Alarcos (1981: 201 y ss) propone la sucesividad sistémica siguiente:

Sistema 1: el sistema fonológico latino

Sistema 2: el sistema fonologico prerromance, como diasistema de las lenguas románicas.

Sistema 3: el sistema fonologico hispano, como diasistema del dominio hispánico.

Sistema 4: el sistema fonológico alfonsí y medieval.

Sistema 5: el sistema fonológico moderno.

Sistema 6: la tendencia fonológica del desequilibrio del sistema actual, que prepara el próximo sistema futuro.

Nos detendremos en la consideración del proceso dinámico y reestructuración que ofrecen las sibilantes al participar en la conversión del Sistema 4 en Sistema 5, fenómeno que, por conocido, nos ahorrará detalles explicativos.

En una primera observación está el hecho sociolingüístico del triunfo de la norma castellana vieja sobre la toledana, apoyado en el hecho fonético-fonológico de la pérdida de la distinción sonora / sorda, en beneficio de las variantes sordas, en los pares de sibilantes

$\begin{array}{ll}\text { ápico-dentales fricativas } & / \mathbf{z}, \mathbf{s} / \\ \text { dorso-dentales africadas } & \mid / \mathbf{z}, \mathbf{s} / \\ \text { prepalatales fricativas } & \mid \mathbf{z}, \mathbf{s} /\end{array}$

Estos pares se igualan fonéticamente (cfr A. Alonso, 1967 y 1969; R. Lapesa, 1980: 283; E. Alarcos, 1981: 262), produciéndose una desfonologización y originándose, en consecuencia, el establecimiento de una alternancia alofónica en cada par. 
Mas, inmediatamente se debe observar la instauración de un nuevo conjunto de relaciones por causa de nuevas transfonologizaciones puesto que, simultáneamente,

a) el par alofónico de las antiguas palatales $/ \check{z}, \$ /$ se velariza, dando lugar $a / x /$ como fricativa velar sorda.

b) el par alofónico de las antiguas africadas dentales $/ \hat{z}, \hat{\mathrm{s}} / \mathrm{se}$ interdentaliza y pierde el elemento oclusivo, dando lugar a $/ \theta /$ como interdental fricativa sorda.

Se habrá advertido cómo un cambio fonológico es siempre una repercusión en el sistema de uno o más, generalmente varios, cambios fonéticos. Y cómo, en el caso contemplado, hemos aplicado criterios de evolución absoluta, de evolución relativa, de influencia del entorno socioparlante, al lado de criterios fonológicos del sistema. Pero aquí se da también una motivación interna ( $\mathrm{cfr} \mathrm{Cl}$. Hagège - A.G. Haudricourt, 1978) donde el dinamismo sistémico opera con criterios de rendimiento funcional y economía ya que, en opinión de A. Martinet (1964: 54 y ss.) el cambio no se da con independencia de las necesidades de la comunicación.

Efectivamente. El sistema fonológico medieval ofrecía estos tres tríos correlativos
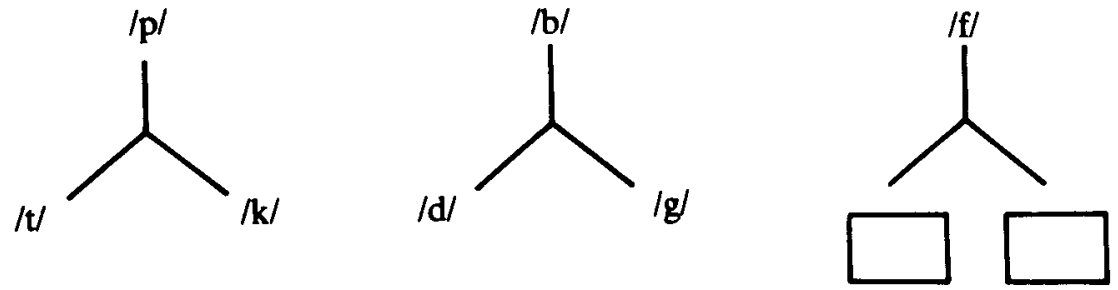

con una labial, una dental y una velar en cada uno, siendo el primero oclusivo sordo, el segundo oclusivo sonoro y el tercero fricativo sordo pero... con dos casillas vacías. Al llenarse estos vacíos, las casillas obligan sistémicamente a una perfección interna con nuevos conjuntos fonémicos "predestinados", diríamos, en sus rasgos o marcas caracteristicas de pertinencia:

a) una dental, al igual que $/ \mathrm{t} / \mathrm{y} / \mathrm{d} /$, mas fricativa sorda como $/ \mathrm{f} /$; 
b) una velar, al igual que $/ \mathbf{k} / \mathrm{y} / \mathrm{g} /$, pero fricativa sorda, nuevamente, para formar parte del trío con $/ f /$ :

es decir, precisamente los fonemas $/ \theta / \mathrm{y} / \mathrm{x} /$ que hemos visto aparecer en el nuevo sistema fonológico moderno que se mantiene aún hoy.

En cuanto al paso dinámico del Sistema 5, moderno y actualmente vigente o normativamente mantenido, hacia el Sistema 6, aún no estabilizado pero que puede preverse en el desequilibrio de la estabilidad del Sistema 5, se advierten otras tendencias internas activas que se dirigen a la reestructuración entre los fonemas

/ĉl única africada del sistema

/s/ única sibilante medieval que permaneció

$/ y /$ palatal central que se beneficia de la preponderancia del yeísmo a costa de la $/ /$ palatal lateral.

Es decir, la tendencia al cambio sistémico se sitúa en la relación instaurada en

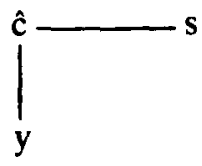

Porque la realización de /s/ en la región cantábrica tiende a palatizarse: $\rightarrow[\xi]$; y en la Andalucía sevillana la realización de /ĉl tiene a hacerse fricativa: $\rightarrow[\check{s}]$.

Puesto que el sonido fonético evoluciona y cambia progresivamente, aparece la diversidad de normas coexistentes. Pero el fonema no evoluciona sino es sustituido en el conjunto sistémico de relaciones internas. Al comprobar la variedad fonética de realizaciones, puede preverse la tendencia del dinamismo sistémico e, incluso, proponer hipótesis de futuribles estados fonológicos. Sin embargo, nunca en exactitud de predicción ya que, como sucede en el comportamiento humano, en el sistema se da con frecuencia la regeneración lingüística con fuerzas en vaivén: a diferencia de lo que ocurre en lo biologico, en la lengua puede recuperarse un estado anterior que parecía ya decaído. 


\subsection{Comportamiento histórico sistémico en lo sintáctico}

Con ocasión de nuestra tesis doctoral, hace ya años, dedicamos una particular atención investigadora al comportamiento formal y funcional de los demostrativos pronominales y adjetivos en el contraste orientador de distintas lenguas románicas (cfr V. Lamiquiz, 1967).

Hemos mantenido la curiosidad investigadora en este ámbito de la deíxis ya que pensamos que el espacio y el tiempo constituyen las dos coordenadas humanas fundamentalmente esenciales. $Y$, comprensiblemente, la lengua alcanza a plasmarlas de manera utilitaria y vital en la comunicación. Por una parte, el hecho de señalar y localizar los contenidos responde a una necesidad elemental intercomunicativa. Y, por otro lado, nos encontramos en este dominio con una amplia complejidad de formas mostrativas que, en sabia economía y rentabilidad, la lengua sabe seleccionar y sistematizar con su coherencia interna propia.

Nos detendremos ahora en la observación del comportamiento histórico de los adverbios mostrativos y precisaremos su organización sistémica diacrónica en nuestra lengua española, aunque restringiendo nuestro análisis a la brevedad que las circunstancias del momento requieren.

La lengua latina nos ofrece la base fundamental de las necesidades comunicativas a que nos referíamos, con este entramado de formas (cfr A. Ernout, 1973: 94):

\begin{tabular}{l|lll|l} 
Quis? & is $\sim$ hic & iste & ille & \\
\hline Ubi? & ibi $\sim$ hic & istic & illic & 'alli' ... \\
Unde? & inde $\sim$ hinc & istinc & illinc & 'de alli' ... \\
Quo? & eo $\sim$ huc & istuc & illuc & 'hacia allí ... \\
Qua? & ea $\sim$ hac & istac & illac & 'por alli' ...
\end{tabular}

A la pregunta inicial situacional acerca del lugar, origen, meta o paso, responden las correspondientes formas matizando esas posiciones deícticas.

La lengua romance adopta muy pronto las formas $y<i b i$ así como ende < inde. Mas también hereda los refuerzos latinos de insistencia que las formas deícticas debilitadas, tanto en su señalación como en cuanto cuerpo de vocablo, fueron adquiriendo. El refuerzo más empleado había sido ecce, epidíctico por excelencia el cual, debilitado a su vez, se hace eccum < ecce eum. Y de la fusión atque eccum > 
*accu de la lengua hablada frente al ecce literario, en opinión de W. Meyer-Lübke (1890-1906), aunque E. Bourciez (1956: 241) da como refuerzo ecce para la Galia del norte y accu para la Península, y D. Alonso (1943: 41-42) propone como quizá más posible la forma ${ }^{*} a k k$ we.

Como consecuencia de ello, encontramos en nuestros textos medievales las siguientes formas adverbiales mostrativas:

$\begin{array}{cl}\begin{array}{c}\text { y } \sim \text { aquí } \\ \text { ende } \sim \text { aquende }\end{array} & \text { allí } \\ \text { acó } & \text { allende } \\ \text { acá } & \text { alló } \\ & \text { allá, acullá }\end{array}$

Ante esta variedad, hemos sido tentados por la curiosidad investigadora de comprobar su empleo. $Y$ hemos recurrido a un muestreo de uso en algunas obras representativas de los siglos medievales. He aquí los datos cuantitativos absolutos con los valores porcentuales que permiten su contraste relativo:

\begin{tabular}{l|c|c|c|c|c|c|c|c} 
& $y$ & aqui & acd & alli & alla & ende & aquende & allende \\
\hline Cantar de Mio Cid & 56 & 30 & 10 & 22 & 19 & 29 & 4 & 5 \\
& $32 \%$ & $17 \%$ & $5,5 \%$ & $13 \%$ & $11 \%$ & $16,5 \%$ & $2 \%$ & $3 \%$ \\
Gonzalo de Berceo & 36 & 12 & 0 & 7 & 12 & 10 & 1 & 3 \\
& $44 \%$ & $15 \%$ & $0 \%$ & $9 \%$ & $15 \%$ & $12 \%$ & $1,2 \%$ & $3,8 \%$ \\
1. Crónica General & 350 & 89 & 4 & 192 & 45 & 44 & 0 & 2 \\
& $48 \%$ & $13 \%$ & $0,5 \%$ & $26,2 \%$ & $6 \%$ & $6 \%$ & $0 \%$ & $0,3 \%$ \\
Libro de Buen Amor & 36 & 52 & 3 & 42 & 11 & 5 & 0 & 0 \\
Enrique de Villena & $24 \%$ & $35 \%$ & $2 \%$ & $28 \%$ & $7,5 \%$ & $3,5 \%$ & $0 \%$ & $0 \%$ \\
& 1 & 30 & 0 & 63 & 4 & 14 & 0 & 0 \\
& $0,9 \%$ & $27 \%$ & $0 \%$ & $56 \%$ & $3,5 \%$ & $12,6 \%$ & $0 \%$ & $0 \%$
\end{tabular}

Al situar esas frecuencias de uso en el eje diacrónico, puede captarse la progresiva selección de formas mostrativas adverbiales. Además, esas cifras nos permiten precisar ciertas preferencias de uso progresivo entre algunos deícticos alternativos. Así, por ejemplo, 
a) entre la forma simple $y$ y la reforzada aquí, según el gráfico I que se manifiesta bastante sintomático (véase el Gráfico I adjunto).

b) entre las formas alli y alla, en el gráfico II igualmente informativo (véase el Gráfico II adjunto).

Al contemplar las tendencias de uso en esos datos cuantitativos porcentuales, tanto numérica como gráficamente, se confirma la transcendencia e importancia de los cambios que la lengua española experimenta en el siglo XIII.

Pero vamos ahora a contemplar cómo funcionan sistémicamente esos adverbios mostrativos y el dinamismo interno que ofrecen. En la observación de los valores funcionales que muestran los textos de nuestra documentación en muestreo, podemos señalar los siguiente sistemas organizados.

Sistema A: Cantar de Mio Cid

$$
\begin{aligned}
& y \sim a q u i ́ \\
& 1 \\
& a c a ́
\end{aligned}
$$<smiles>[GeH2]</smiles>

En este sistema, además de la alternancia formal entre $y \sim a q u i$, queda instalado un criterio de referencia mostrativa fundamentado únicamente en la distancia: cerca / lejos, como en el sistema deíctico francés de hoy.

Con este criterio de distancia aparece en el sistema una doble oposición. Por una parte,

lo cercano frente a lo alejado:

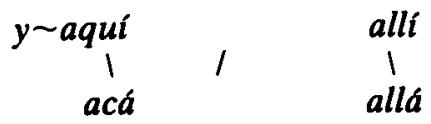


Gráfico I

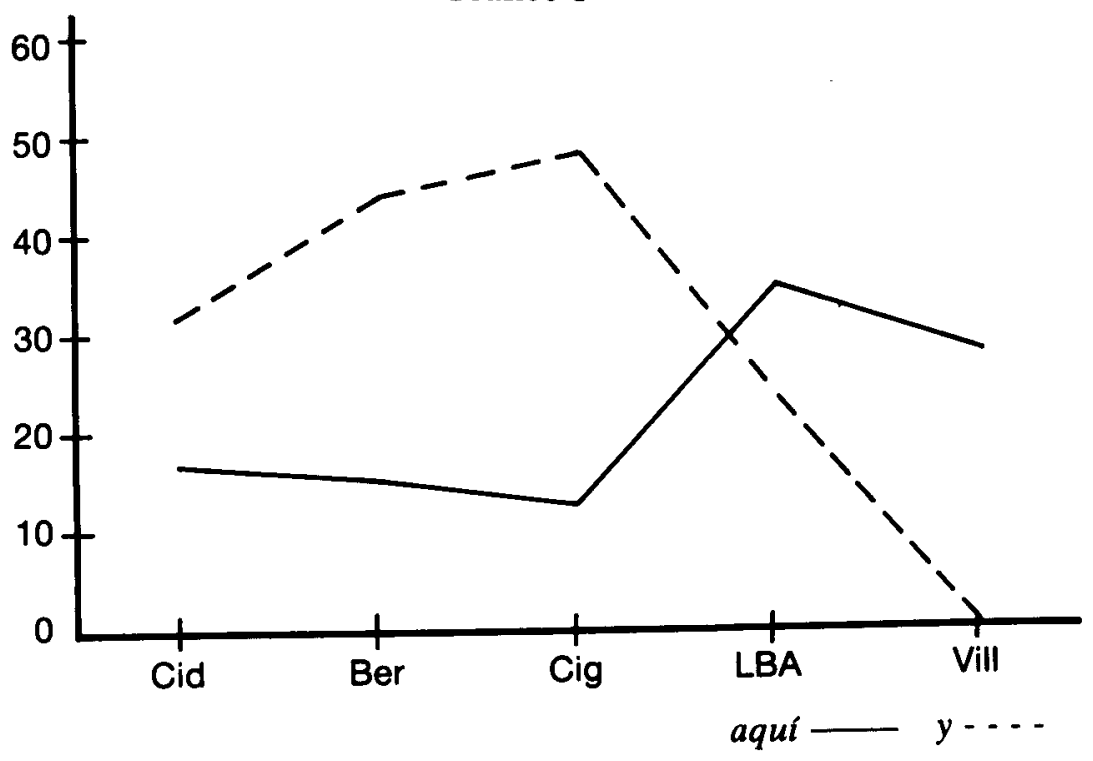

Gráfico II

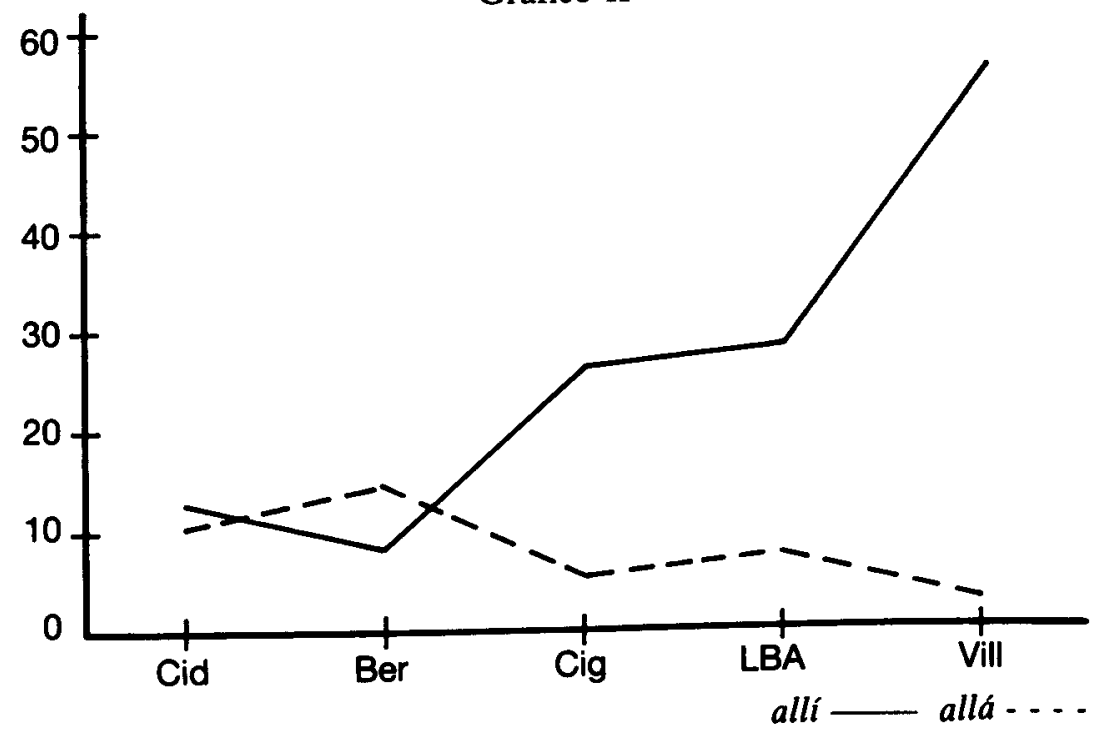


Y, por otro lado, en cada miembro de la oposición se instala la dialéctica funcional entre

lo inmediato frente a lo próximo:

$$
y \sim \text { aqui } \quad / \quad \text { acá }
$$

así como

lo alejado frente a lo muy alejado:

$$
\text { allí } \quad \text { allá }
$$

esta forma segunda allá con el significado de 'la otra vida'.

$$
\begin{aligned}
& \text { Sistema B: Gonzalo de Berceo } \\
& 1^{a} \text { Crónica General } \\
& \begin{array}{ccc}
y \sim a q u i \sim a h i & \mid & \text { allí } \\
I & & l \\
\text { acá } & & \text { allá }
\end{array}
\end{aligned}
$$

Continúa la referencia funcional mostrativa de la distancia objetiva como marca dialéctica oposicional. En cuanto a las formas deícticas que manifiestan ese funcionamiento sistémico, conviene anotar cierta decadencia de acá y la aparición de ahí con el significado de 'en el lugar mencionado'. Y está claro (J. Corominas - J.A. Pascual, 1983: s.v. $a h i$ ) que esta forma ahi no debe separse de $y$ puesto que ambos deícticos durante la Edad Media ofrecen los mismos usos y los mismos valores sistémicos: únicamente puede diferenciarse porque ahi es tónico mientras que $y$ puede ser átono.

Sistema C: Libro de Buen Amor

$$
\begin{array}{r}
y \sim a h i \sim a q u i \\
1 \\
a c a ́
\end{array}
$$

$$
\begin{gathered}
\text { alle } \\
1 \\
\text { alla }
\end{gathered}
$$


El sistema de los adverbios mostrativos en este siglo XIV se mantiene funcionalmente con la marca de referencia constituída por la distancia objetiva. Se inicia ya una tendencia, que triunfará más tarde, consistente en neutralizar la oposición doble entre

$$
\text { aqui / acá y alli / allá }
$$

Se encaminan históricamente a hacerse alomórficas en cada par o bien, como consecuencia de ello, a distribuirse geográficamente con preferencia de empleo

$$
\begin{aligned}
& \text { ya por aqui / alli } \\
& \text { ya por acá / allé. }
\end{aligned}
$$

Sistema D: Enrique de Villena

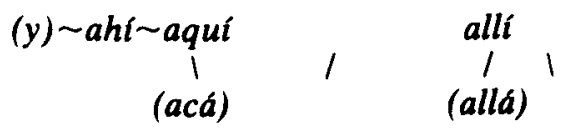

El sistema permanece funcionalmente como el anterior. Pero sus formas ofrecen un alto índice de selección que prepara el sistema clásico.

Porque, efectivamente, hay que llegar hasta La Celestina en 1502 para que aparezca por primera vez el valor de ahi como 'el lugar donde estás tú' (Ibídem).

Se inicia así la referencia mostrativa personal en el sistema: o sea, la referencia de proximidad no absoluta sino relativa al yo tú el. El sistema deíctico binario de toda la Edad Media se hace sistema ternario. Es el

Sistema E: a partir del siglo XVI

$\underset{(a c a ́)}{a q u i}$ / ahi / $\begin{gathered}\text { alli } \\ \text { (allá) }\end{gathered}$


Se ha de notar, sin embargo, que no llega a desaparecer la referencia deíctica situacional, especialmente en el mostrativo ahí que, en uso independiente, conserva el valor anafórico originario. La referencia deíctica personal se afianza en deíxis ternaria y las formas ya seleccionadas serán las que funcionen en nuestra lengua clásica y permanecen en nuestro sistema adverbial mostrativo actual.

\section{BibLIOGRAFIA}

E. Alarcos (1981) Fonología española. Madrid, Ed. Gredos, $3^{\text {A }}$ ed.

A. Alonso (1967 y 1969) De la pronunciación medieval a la moderna en español. Madrid,

Ed. Gredos. (Ultimados y puestos para la imprenta por $\mathbf{R}$. Lapesa)

D. Alonso (1943) "Etimologías hispánicas" RFE, Madrid, XXVII, 41-42.

E. BourCiEz (1956) Eléments de linguistique romane. Paris, Nathan, $4^{c}$ ed

TH. BYNON (1981) Lingüística histórica. Madrid, Ed. Gredos.

J. Corominas - J.A. Pascual (1983) Diccionario crítico etimológico castellano e hispánico.

Madrid, Ed. Gredos, 6 vol.

E. COSERIU (1958) Sincronia, diacronia e historia. Montevideo, Universidad.

- (1962) "Determinación y entorno" en Teoría del lenguaje y lingüística general.

Madrid, Ed. Gredos.

(1977) Principios de semántica estructural. Madrid, Ed. Gredos.

(1977) Estudios de lingüistica románica. Madrid, Ed. Gredos.

C. HAGÉge - A.G. HAUdricourt (1978) La phonologie diachronique. Paris, PUF

R. JAKOBSON (1931) "Principes de phonologie historique" en TCLP, IV, 247-267.

W. LABOV (1972) "Internal Evolution of Linguistic Rules" en Linguistic Change and Generative Theory. Bloomington, Indiana U.P.

V. LAMIOUIz (1967) "El demostrativo en español y en francés" en $R F E, L, 163-202$. (1985) El contenido lingüistico. Barcelona, Ed. Ariel.

R. LAPESA, (1980) Historia de la lengua española. Madrid, Ed. Gredos, $8^{2}$ ed. (1984) "Los francos en la Asturias medieval y sus influencias lingüísticas" en Symposium sobre cultura asturiana de la Alta Edad Media: 1961. Recogido en Estudios de historia lingüistica española. Madrid, Paraninfo, pp. 43-52, según el cual cito.

E. LiTTRE (1958) Dictionnaire de la langue française. Paris, Editions Universitaires. (Cito según esta edición abreviada.)

Y. MALKIEL (1976) "From Romance Philologie through Dialect Geography to Sociolinguistics" en J.P. Rona - W. Wölk (ed) The Social Dimension of Dialectology. Bloomington, Indiana U.P.

B. Malmberg (1966) Les nouveaux chemins de la linguistique. Paris, Colin. Trad. esp. Los nuevos caminos de la lingüística. México, Siglo XXI, 1967.

A. MARTinet (1964) Economie des changements phonétiques. Bern, A. Francke. Trad. esp. Economía de los cambios fonéticos. Madrid, Ed. Gredos, 1974.

W. MEYER-LÜBKe (1980-1906) Grammaire des langues romanes. Paris (en trad. francesa), V. 11.

L. MiChelena (1963) Lenguas y protolenguas. Salamanca, Ed. Universidad. (1967) "Estructuralismo y reconstrucción" en Principios y problemas del estructuralismo lingütstico. Madrid, CSIC, pp. 299-319. Recogido en Lengua e historia. Madrid, Paraninfo, 1985, pp. 9-22. 
C. Pensado (1983) El orden histórico de los procesos fonológicos. Salamanca, Ed. Universidad.

(1984) Cronología relativa del castellano. Salamanca, Ed. Universidad.

Real ACademia Española (1984) Diccionario de la lengua española. Madrid, Espasa-Calpe, 2 vol.

R. H. RoBıns (1984) Breve historia de la lingǘstica. Madrid, Ed. Gredos.

\section{Textos seleccionados para el muestreo}

Cantar de Mio Cid: Hemos empleado la ed. de R. Menéndez Pidal.

Gonzalo de Berceo: Nos hemos basado en Martirio de San Lorenzo. Ed. Pompilio Tesauro.

Nápoles, 1971.

Poema de Santa Oria. Ed. I.Uría. Logroño, 1976. Vida de Santo Domingo de Silos. Ed. G. Orduna. Salamanca, 1968.

La vida de San Millán de la Cogolla. Ed. B. Dutton. Londres, 1967.

y una selección de Milagros de Nuestra Señora. Ed. A.G. Solalinde. Madrid, 1964.

1" Crónica General: Publicada por R. Menéndez Pidal, con la colaboración de A. G. Solalinde, M. Muñoz Cortés y J. Pérez Gómez. Hemos seleccionado las páginas: $6-31,85-101,200-227,300-320,400-426,700$. 708 .

Libro de Buen Amor: Hemos empleado la ed. de J. Corominas. Madrid, 1967

Enrique de Villena: Hemos utilizado los Doze Trabajos de Hércules. Ed. M. Morreale. Madrid, 1958.

Arte Cisoria. Ed. F.B. Navarro. Madrid, 1879.

Arte de Trovar. Ed. F.J.Sánchez Cantón. Madrid, 1923. 